\title{
Correlation between ADR of screening and all colonoscopies
}

\author{
Ivana Mikoviny Kajzrlikovaa , Petr Vitek ${ }^{b}$, Josef Chalupaa , Jan Kuchara, Jiri Platos ${ }^{\mathrm{a}}$, Pavel Reha ${ }^{\mathrm{a}}$, Pavel Klvana jr. ${ }^{\mathrm{a}}$
}

\begin{abstract}
Background and Aims. Colonoscopy with polypectomy are associated with a reduction in the incidence of colorectal cancer (CRC), as well as mortality, secondary to CRC. Because of the variation in physicians' performance and the risk of interval CRC after a colonoscopy, several quality indicators have been established. ADR (adenoma detection rate) is a generally accepted quality indicator. But it is also a target of possible gaming and achieving an adequate number of colonoscopies only from screening may be a problem for some practices. The aim of this study was to compare ADR for colonoscopies done for various indications and to look for correlations between the ADR of screening and all examinations.
\end{abstract}

Methods. We retrospectively assessed the quality indicators of all colonoscopies performed in a nonuniversity hospital, Frydek-Mistek, from January 2013 to December 2017. We calculated the ADR for all colonoscopies in patients over 50 years of age (subdivided into screening, surveillance, diagnostic) and separately only for screening colonoscopies. Correlations were made using the Pearson's correlation coeficient.

Results. The sample was composed of 6925 patients over 50 years of age (3620 men, 3305 women, mean age 66.2 years). The ADRs for screening and surveillance were higher than for diagnostic colonoscopies for all of the endoscopists, and the ADRs for all colonoscopies were lower than for screening, but sufficiently over $25 \%$. There was a positive correlation between the ADR of screening and all colonoscopies $(r=0.906, P<0.005)$.

Conclusions. The calculation of ADR for all colonoscopies was possible in our endoscopic department, and there was a positive correlation with ADR for screening colonoscopies. ADR for all colonoscopies is a good tool for calculating real ADR from large sample sizes without gaming.

Trial Registration: ClinicalTrials.gov (NCT03730441).

Key words: adenoma, colorectal neoplasms, colonoscopy, quality improvement, standards, screening

Received: October 18, 2020; Revised: November 23, 2020; Accepted: November 24, 2020; Available online: December 16, 2020 https://doi.org/10.5507/bp.2020.059

(c) 2021 The Authors; https://creativecommons.org/licenses/by/4.0/

${ }^{a}$ Beskydy Gastrocentre, Internal Medicine Department, Hospital Frydek-Mistek, Czech Republic

${ }^{b}$ Beskydy Gastrocentre, Hospital Frydek-Mistek and Faculty of Medicine, University of Ostrava, Czech Republic

Corresponding author: Ivana Mikoviny Kajzrlikova, e-mail: kajzrlikova@nemfm.cz, Ivanakaj@seznam.cz

\section{BACKGROUND AND AIMS}

Colonoscopy with polypectomy is associated with a reduction in the incidence of colorectal cancer (CRC), as well as mortality secondary to CRC (ref. ${ }^{1,2}$ ). Because of the variation in physicians' performance and the risk of interval CRC after a colonoscopy, several quality indicators have been established. ADR (adenoma detection rate) is the number of patients with one or more adenomas removed during screening colonoscopy in patients age 50 years or older, and it is a generally accepted quality indicator ${ }^{3}$. ADR reflects the adequate inspection of the bowel mucosa, and it has been inversely associated with the risk of interval CRC and CRC death ${ }^{4,5}$. Corley et al. ${ }^{6}$ presented a $3 \%$ reduction in CRC incidence and a 5\% reduction in CRC mortality for each $1 \%$ increase of ADR. The minimum target for overall ADR is at least 25\% (30\% for men, $20 \%$ for women) ( ref. $^{7}$ ).

For possible gaming with ADR, other indicators have been discussed. PDR (polyp detection rate) is defined as the proportion of patients with one or more polyps removed during screening colonoscopy in patients age 50 years or older. Calculating PDR does not require histopathology data; thus, it can be useful in the "resect and discard" strategy, and it correlates well with ADR ( ref. $^{8,9}$ ). With an average adenoma-to-polyp detection ratio of 0.64 , the minimum standard PDR was estimated at $40 \%$, which corresponds to an ADR of 25\% (ref. $\left.{ }^{4}\right)$. On the other hand, calculating PDR can lead to the removal of clinically insignificant lesions, for example, distal colon diminutive hyperplastic polyps. MAP (mean adenoma per colonoscopy) or APCR (adenoma per colonoscopy rate) calculate all adenomas found and removed during a procedure and reflect the quality of the examination of the entire length of the colon. It is considered to be the most objective quality indicator. But MAP was proven not to be superior to ADR in a study by Kaminsky et al. ${ }^{10}$.

One way of possible gaming with ADR is the so-called one and done strategy. Because only one adenoma is needed, after the removal of the first adenoma, the re- 
maining colon can be examined less carefully ${ }^{11}$. Another way of gaming with ADR is changing the colonoscopy indication. The doctor can call the examination a screening examination if an adenoma has been detected, and a diagnostic examination using patient's symptoms as the indication if no adenoma was detected. This can be solved by calculating the overall ADR instead of the screening ADR (ref. ${ }^{12}$ ).

Also achieving of an adequate number of colonoscopies only from screening could be a problem for some practices.

The aim of this study was to compare ADR for colonoscopies performed for various indications and to look for correlations between the ADR of screening and all examinations.

\section{METHODS}

We retrospectively assessed the quality indicators of all colonoscopies performed in the nonuniversity hospital Frydek-Mistek from January 2013 to December 2017. The data from all colonoscopies performed at FrydekMistek are recorded in our database. The database contains epidemiologic data about the patient (age, gender, antiplatelet and anticoagulation therapy, family history of colorectal cancer), data about the examination (type of examination, indication, sedation, bowel preparation, cecal intubation, number of lesions), histologic results, and complications.
The colonoscopies were performed by 6 experienced endoscopists-gastroenterologists. All examinations were performed using high-definition endoscopes.

The study was approved by the local institutional review board. The local institutional review board granted exemption from informed consent with the study, as the patients were receiving the standard of care, the data collection did not influence the medical practice, and the data was deidentified before the analysis. All patients signed an informed consent with colonoscopy. The study was registered on ClinicalTrials.gov (NCT03730441).

The data of patients over 50 years of age scheduled for colonoscopy between January 2013 and December 2017 were included. Study indications were grouped into the following categories: screening, surveillance, and diagnostic. Therapeutic examinations, IBD, the management of complications, and sigmoidoscopies were excluded from the study.

A correlation analysis was performed using Pearson's correlation coeficient, multiple chi square test was used to compare the patients' age, and one way ANOVA was used to compare the proportion of men and women among endoscopists; $P<0.05$ was considered significant. The statistical analysis was calculated using SPSS (version 19.0).

\section{RESULTS}

In the study period, 10,472 colonoscopies and sigmoidoscopies were done in total. Sigmoidoskopies and

Table 1. Data of all 6 endoscopists in the endoscopic department together.

\begin{tabular}{cccccccccc}
\hline & \multicolumn{2}{c}{ All indications } & \multicolumn{2}{c}{ Screening } & \multicolumn{2}{c}{ Surveillance } & \multicolumn{2}{c}{ Diagnostic } \\
$\mathrm{n}$ & Age & Men\% & ADR & $\mathrm{n}$ & ADR & $\mathrm{n}$ & ADR & $\mathrm{n}$ & ADR \\
\hline 6925 & 66.2 & 52.3 & 42.6 & 2099 & 46.4 & 1875 & 48.7 & 2951 & 36.1 \\
\hline
\end{tabular}

Table 2. Number, age, proportion of men, and ADR of all colonoscopies.

\begin{tabular}{ccccc}
\hline & \multicolumn{4}{c}{ All indications } \\
Endoscopist & $\mathrm{n}$ & Age & Men\% & ADR \\
\hline 1 & 1467 & 65.4 & 51.1 & 39.1 \\
2 & 419 & 65.8 & 58.0 & 47.0 \\
3 & 815 & 66.3 & 49.3 & 37.7 \\
4 & 1394 & 66.2 & 53.7 & 41.7 \\
5 & 2406 & 66.6 & 51.8 & 45.0 \\
6 & 424 & 66.8 & 54.2 & 48.6 \\
\hline
\end{tabular}

Table 3. Number and ADR of screening, surveillance, and diagnostic colonoscopies.

\begin{tabular}{ccccccc}
\hline & \multicolumn{2}{c}{ Screening } & \multicolumn{2}{c}{ Surveillance } & \multicolumn{2}{c}{ Diagnostic } \\
Endoscopist & $\mathrm{n}$ & ADR & $\mathrm{n}$ & ADR & $\mathrm{n}$ & ADR \\
\hline 1 & 567 & 41.3 & 380 & 45.3 & 520 & 32.1 \\
2 & 146 & 49.3 & 186 & 52.7 & 87 & 31.0 \\
3 & 170 & 40.0 & 226 & 48.7 & 419 & 30.3 \\
4 & 430 & 49.3 & 379 & 44.6 & 585 & 39.4 \\
5 & 700 & 48.3 & 589 & 52.8 & 1117 & 38.9 \\
6 & 86 & 57.0 & 115 & 47.0 & 223 & 46.2 \\
\hline
\end{tabular}


colonoscopies with indication therapeutic, IBD and management of complications were excluded from the study. The group for statistics was composed of 6925 patients (3620 men, 3305 women, mean age 66.2 years, $\mathrm{SD} \pm 9.2$ years) who underwent screening (2099 patients), surveillance (1875 patients), or diagnostic colonoscopy (2951 patients). The data of all 6 endoscopists in the endoscopic department together are mentioned in Table 1.

Among the 6 endoscopists, there were differences in the proportion of men and women $(P=0.048)$ and age of patients $(P=0.002)$ (see Table 2$)$. This should be taken into consideration when comparing various endoscopists, but it does not affect the correlation analysis of ADR from all and screening colonoscopies. The only female endoscopist (Number 3 ) had a higher proportion of female patients ( $50.7 \%$ women, $49.3 \%$ men) than her male colleagues.

The ADRs for screening (40-57\%) and surveillance (44.6-52.8\%) were higher than for diagnostic colonoscopies (30.3-46.2\%) for all endoscopists (see Table 3 ). The ADRs for all colonoscopies (37.7-48.6\%) were lower than for screening, but sufficiently over $25 \%$ (see Table 2 ). There was a positive correlation between the ADR of screening and all colonoscopies $(\mathrm{r}=0.906, P<0.005)$.

\section{DISCUSSION}

The quality of the colonoscopic examination is now considered to be one of the most important parts of all CRC screening programs. It has been proved that a lower quality of the exam can result in interval colon cancers and that this trend can be prevented by the appropriate training of endoscopists with low ADR (ref. ${ }^{5}$ ). Various quality indicators of colonoscopic examinations were established in the current guidelines from 2017, preprocedure, related to the procedure, and postprocedure ${ }^{4}$. ADR is the gold standard, but it has several limitations, and there is a space for possible gaming.

A possible way of gaming with ADR, "indication gaming" is changing the colonoscopy indication, when patients have multiple indications for a colonoscopy. The doctor can call the examination a screening examination if an adenoma has been detected, or a diagnostic examination using the patient's symptoms as the indication if no adenoma was detected. This can be solved by calculating the overall ADR instead of the screening ADR (ref. ${ }^{12}$ ). In a study performed by Rex et al. from 2017, after "the indication gaming" in patients with both screening and diagnostic indication, a single expert colonoscopist was able to increase his apparent screening-only ADR from $48.8 \%$ to $55.1 \%$ (ref. $^{12}$ ).

Our study compared ADR for colonoscopies done for various indications. The ADR for all endoscopists in our study was $46 \%$ for screening and $42 \%$ for all colonoscopies, which exceeds the current quality standards. The ADRs for screening and surveillance were higher than for diagnostic colonoscopies for all endoscopists. The ADRs for all colonoscopies were lower than for screening, but sufficiently over the recommended value of $25 \%$.
There was a positive correlation between the ADR of screening and all colonoscopies, so it is feasible to substitute screening ADR by overall ADR in daily practice. The advantage of overall ADR is in reducing "the indication gaming“, as was previously mentioned. Moreover, calculating ADR from a higher number of examinations compared with only from screening is more reliable. For practices in which there are more surveillance and diagnostic colonoscopies, achieving an adequate number of screening examinations could be a problem. In a study by Do et al., large sample sizes (eg, 500) were required for a reliable assessment of an endoscopist's ADR (ref. ${ }^{13}$ ). Also important, Corley's study proving a strong relationship between lower ADR and a higher risk of interval CRC was performed for screening, surveillance, and the evaluation of symptoms, not only for screening colonoscopies ${ }^{6,14}$. The overall ADR may not be significantly altered by the patients mix, and it may still be an important quality measure ${ }^{14,15}$. Also, in a study calculating not the ADR, but the PDR of polyps $\geq 5 \mathrm{~mm}$, the differences in PDR $-5 \mathrm{~mm}$ between the clinical and screening colonoscopies could be explained by the endoscopist; the PDR-5 $\mathrm{mm}$ benchmarks may be similar for clinical and screening colonoscopies ${ }^{16}$. The demographic mix may be far more important than the procedural indication for the calculation of ADR. Age and sex really make a difference. It may make more sense to calculate ADR by sex and age than by indication ${ }^{14,17}$.

In our study, the only female endoscopist had a higher proportion of female patients than her male collegues. There is the possibility that female patients prefer female endoscopists for their colonoscopy. So it may be useful to calculate ADR by sex or to monitor endoscopists' proportion of men and women in daily practice.

The limitations of this study include that it was performed at a single center. All 6 of the endoscopists had overall and screening ADRs above 35\% (screening ADRs above $40 \%$ ). Thus, the results may not be generalizable in centers with lower ADRs.

\section{CONCLUSIONS}

In summary, the calculation of the ADR for all colonoscopies was possible in our endoscopic department, and there was a positive correlation with ADR for screening colonoscopies. Because of the inclusion of diagnostic examinations, the ADR for all colonoscopies was lower than for screening, but still over the recommended values. ADR for all colonoscopies is a good tool for calculating real ADR from large sample sizes without gaming. Calculating ADR by sex or monitoring endoscopists“ proportion of men and women could be helpful in daily practice and could make ADR more objective.

Author contributions: IMK, PV, JCH: the concept and design of the study; IMK: statistical analysis, literature search, manuscript writing; IMK, JK, JP, PR, PK: data acquisition; all authors critically revised the manuscript, approved the final version to be published, and agree to be accountable for all aspects of the work. 
Conflict of interest statement: The authors state that there are no conflict of interest regarding the publication of this article.

\section{REFERENCES}

1. Winawer SJ, Zauber AG, Ho MN, O'Brien MJ, Gottlieb LS, Sternberg SS, Waye JD, Schapiro M, Bond JH, Panish JF. Prevention of colorectal cancer by colonoscopic polypectomy. The National Polyp Study Workgroup. N Engl J Med 1993;329:1977-81. doi: 10.1056/ NEJM199312303292701

2. Nishihara R, Wu K, Lochhead P, Morikawa T, Liao X, Qian ZR, Inamura K, Kim SA, Kuchiba A, Yamauchi M, Imamura Y, Willett WC, Rosner BA, Fuchs CS, Giovannucci E, Ogino S, Chan AT. Long-term colorectalcancer incidence and mortality after lower endoscopy. N Engl J Med 2013;369:1095-105. doi: 10.1056/NEJMoa1301969

3. Rex DK, Petrini JL, Baron TH, Chak A, Cohen J, Deal SE, Hoffman B, Jacobson BC, Mergener K, Petersen BT, Safdi MA, Faigel DO, Pike IM. Quality indicators for colonoscopy. Gastrointest Endosc 2006;63:S1628. doi: 10.1016/j.gie.2006.02.021

4. Kaminski MF, Thomas-Gibson S, Bugajski M, Bretthauer M, Rees CJ, Dekker E, Hoff G, Jover R, Suchanek S, Ferlitsch M, Anderson J, Roesch T, Hultcranz R, Racz I, Kuipers EJ, Garborg K, East JE, Rupinski M, Seip B, Bennett C, Senore C, Minozzi S, Bisschops R, Domagk D, Valori R, Spada C, Hassan C, Dinis-Ribeiro M, Rutter MD. Performance measures for lower gastrointestinal endoscopy: a European Society of Gastrointestinal Endoscopy (ESGE) Quality Improvement Initiative. Endoscopy 2017;49:378-97. doi: 10.1055/s-0043-103411

5. Kaminski MF, Regula J, Kraszewska E, Polkowski M, Wojciechowska U, Didkowska J, Zwierko M, Rupinski M, Nowacki MP, Butruk E. Quality indicators for colonoscopy and the risk of interval cancer. N Engl J Med 2010;362:1795-803. doi: 10.1056/NEJMoa0907667

6. Corley D, Jensen C, Marks A. Adenoma detection rate and risk of colorectal cancer and death. N Engl J Med 2014;370:1298-306. doi: 10.1056/NEJMoa1309086

7. Rex D, Schoenfeld P, Cohen J, Pike I, Adler D, Fennerty MLI, JG, Park W, Rizk M, Shaheen J, Wani S, Weinberg D. Quality indicators for colo- noscopy. Gastrointestinal Endoscopy 2015;81:31-53. doi: 10.1016/j. gie.2014.07.058

8. Williams JE, Holub JL, Faigel DO. Polypectomy rate is a valid quality measure for colonoscopy: results from a national endoscopy database. Gastrointest Endosc 2012;75:576-82. doi: 10.1016/j. gie.2011.12.012

9. Kessler WR, Imperiale TF, Klein RW, Wielage RC, Rex DK. A quantitative assessment of the risks and cost savings of forgoing histologic examination of diminutive polyps. Endoscopy 2011;43:683-91. doi: 10.1055/s-0030-1256381

10. Kaminski M, Wieszczy P, Kolacz A, Rupinski M, Franczyk R, Rupinska $M$, Bretthauer M, Regula J. Comparison of quality measures for detection of neolasia in screening colonoscopy. Volume 83: Gastroinstestinal Endoscopy, 2016: Page AB527 doi: 10.1016/j. gie.2016.03.1067

11. Denis B, Sauleau EA, Gendre I, Exbrayat C, Piette C, Dancourt V, Foll $Y$, Ait Hadad H, Bailly L, Perrin P. The mean number of adenomas per procedure should become the gold standard to measure the neoplasia yield of colonoscopy: a population-based cohort study. Dig Liver Dis 2014;46:176-81. doi: 10.1016/j.dld.2013.08.129

12. Rex DK, Ponugoti PL. Calculating the adenoma detection rate in screening colonoscopies only: Is it necessary? Can it be gamed? Endoscopy 2017;49:1069-1074. doi: 10.1055/s-0043-113445

13. Do A, Weinberg J, Kakkar A, Jacobson BC. Reliability of adenoma detection rate is based on procedural volume. Gastrointest Endosc 2013;77:376-80. doi: 10.1016/j.gie.2012.10.023

14. Lieberman D, Mascarenhas R. Adenoma detection rate: in search of quality improvement, not just measurement. Gastrointest Endosc 2015;82:683-5. doi: 10.1016/j.gie.2015.02.020

15. Marcondes FO, Dean KM, Schoen RE, Leffler DA, Rose S, Morris M, Mehrotra A. The impact of exclusion criteria on a physician's adenoma detection rate. Gastrointest Endosc 2015;82:668-75. doi: 10.1016/j.gie.2014.12.056

16. Hoff G, Botteri E, Hoie O, Garborg K, Wiig H, Huppertz-Hauss G, Moritz V, Bretthauer M, Holme O. Polyp detection rates as quality indicator in clinical versus screening colonoscopy. Endosc Int Open 2019;7:E195-E202. doi: 10.1055/a-0796-6477

17. Lieberman DA, Williams JL, Holub JL, Morris CD, Logan JR, Eisen GM, Carney P. Colonoscopy utilization and outcomes 2000 to 2011. Gastrointest Endosc 2014;80:133-43. doi: 10.1016/j.gie.2014.01.014 